\title{
Evidence of patient self-testing at clinic review: association with glycaemic control
}

\author{
MARTIN B WHYTE, ${ }^{1}$ CHRIS A MANU, ${ }^{2}$ DAVID HOPKINS, ${ }^{2}$ STEPHEN THOMAS³
}

\begin{abstract}
Aims: Home glucose testing and reflection on patterns are important elements of type 1 diabetes self-management. We hypothesised that patients who demonstrated evidence of self-testing by bringing a record book (capillary blood glucose monitoring diary) to clinic would have better glycaemic control than patients with a glucometer alone, or neither record book nor glucometer.

Methods: This was a prospective observational study of 233 consecutive type 1 diabetes patients using basal-bolus insulin. Exclusion criteria were diagnosis of type 1 diabetes within the previous year, current pregnancy, or prior inclusion in this study. We recorded the presence or absence of a record book or glucometer at the clinic, glycated haemoglobin $\left(\mathrm{HbA}_{1 \mathrm{c}}\right)$, and previous structured education attendance.

Results: Of 233 patients, 90 brought a record book, 61 brought a glucometer and 82 brought neither. Mean $\mathrm{HbA}_{1 \mathrm{c}}$ did not differ between patients with a record book $(63 \pm 2 \mathrm{mmol} / \mathrm{mol}[7.9 \pm 0.2 \%])$ or glucometer $(63 \pm 2$ $\mathrm{mmol} / \mathrm{mol}[7.9 \pm 0.2 \%])$, but was higher in those with neither $(77 \pm 2 \mathrm{mmol} / \mathrm{mol}[9.2 \pm 0.2 \%] ; p<0.001)$. Patients bringing a record book were older on average than those with a glucometer or neither $(49.6 \pm 1.7$ vs. $41.2 \pm 1.7$ vs. $40.6 \pm 1.4$ years; $p<0.001$ ) and had longer mean duration of diabetes $(27.9 \pm 2.0$ vs. $19.2 \pm 1.7$ vs. $18.7 \pm 1.6$ years; $\mathrm{p}<0.001$ ). Prior structured education did not predict the presence of a record book or glucometer in the clinic.

Conclusions: Evidence of self-testing at clinic review, either as a record book or glucometer, was associated with improved control compared with those with neither. $\mathrm{HbA}_{1 c}$ did not differ between patients bringing a record book or glucometer. Self-reflection on glucose results is important for type 1 diabetes self-management, irrespective of the recording method used.

Br J Diabetes Vasc Dis 2015;15:75-77
\end{abstract}

School of Biosciences, University of Surrey, Guildford, UK

Department of Diabetes, King's College NHS Foundation Trust, London, UK

Department of Diabetes, Guy's \& St.Thomas' NHS Foundation Trust,

London, UK

Address for correspondence: Dr Martin Whyte

Clinical Senior Lecturer, School of Biosciences, University of Surrey,

Guildford, GU2 7XX, UK

E-mail: m.b.whyte@surrey.ac.uk

http://dx.doi.org/10.15277/bjdvd.2015.015

\author{
Abbreviations and acronyms \\ $\mathrm{HbA}_{1 \mathrm{c}} \quad$ glycated haemoglobin \\ SMBG Self-monitoring of blood glucose
}

Key words: type 1 diabetes, self-monitoring, glucose meter, glycated haemoglobin, structured education

\section{Introduction}

SMBG is recommended as part of the management of type 1 diabetes as it improves glycaemic control. 1-3 $^{-3}$ Furthermore, those who self-test more frequently have incrementally better control, with a $0.25 \%$ decrease in $\mathrm{HbA}_{1 c}$ for each blood glucose test per day, with the additional benefit levelling off at eight tests per day. ${ }^{2,4,5}$ Studies of how to optimise the use of SMBG have focused on its timing ${ }^{6}$ or frequency, ${ }^{2,4}$ or have compared SMBG with real-time glucose sensors. ${ }^{7}$

Historically, it was believed that keeping a written record would encourage the patient to acknowledge their SMBG results and to contemplate the potential adjustments they could make to insulin dosing in response to nutritional intake and activity. The new generation of devices for SMBG have sophisticated software capable of presenting cumulative data in a variety of graphical and tabular forms that includes mealtime and activity tracking. Before such devices become readily available, we studied whether evidence of a written record of testing at the time of routine clinic review was associated with a better $\mathrm{HbA}_{1 c}$ than those with a meter alone, or those with neither a record book for glucose readings (a capillary blood glucose monitoring diary) nor a glucometer.

\section{Methods}

This was a prospective observational study of patients with type 1 diabetes attending secondary care follow-up clinics at two sites in south London. All patients had a diagnosis of type 1 diabetes for at least one year and were being treated with a basal-bolus regime (at least four injections per day), with scheduled once- or twiceyearly follow-up. Patients using continuous subcutaneous insulin delivery or a real-time glucose monitor were excluded.

Data were collected at the time of consultation with a diabetes physician and included $\mathrm{HbA}_{1 c}$; the presence or absence of a record book, a glucometer, or both, when attending the clinic; and any history of prior attendance for structured education. No patient was studied more than once.

The effect size (partial eta-squared) of age on $\mathrm{HbA}_{1 c}$ was $0.073(p<0.0001)$, which is considered a medium effect. ${ }^{8}$ We 
Table 1 Characteristics of the study population

\begin{tabular}{|c|c|c|c|}
\hline & \multicolumn{3}{|c|}{$\begin{array}{c}\text { Evidence of testing brought to } \\
\text { clinic review }\end{array}$} \\
\hline & $\begin{array}{l}\text { Record book } \\
(n=90)\end{array}$ & $\begin{array}{l}\text { Glucometer } \\
(n=61)\end{array}$ & $\begin{array}{l}\text { Neither } \\
(n=82)\end{array}$ \\
\hline $\begin{array}{l}\text { Male/female, } \\
\text { number (\%) }\end{array}$ & $41(46) / 49(54)$ & $35(57) / 26(43)$ & $50(61) / 32(39)$ \\
\hline Mean age, years & $49.6 \pm 1.7^{*}$ & $41.2 \pm 1.7$ & $40.6 \pm 1.4$ \\
\hline $\begin{array}{l}\text { Mean duration of } \\
\text { diabetes, years }\end{array}$ & $27.9 \pm 2.0^{\dagger}$ & $19.2 \pm 1.7$ & $18.7 \pm 1.6$ \\
\hline $\begin{array}{l}\text { Number (\%) with prior } \\
\text { attendance at structured } \\
\text { education }\end{array}$ & $46(51)$ & $27(44)$ & $32(39)$ \\
\hline $\begin{array}{l}\text { Number (\%) using } \\
\text { insulin analogues } \\
\text { Basal } \\
\text { Prandial }\end{array}$ & $\begin{array}{l}80(89) \\
81(90)\end{array}$ & $\begin{array}{l}56(92) \\
61(100)\end{array}$ & $\begin{array}{l}76(93) \\
81(99)\end{array}$ \\
\hline
\end{tabular}

therefore compared age-adjusted $\mathrm{HbA}_{1 \mathrm{c}}$ between groups (record book, glucometer, neither) using ANCOVA. Tukey's test was used for post-hoc comparisons between group means after adjustment for the effect of this covariate. Fisher's exact test was used to compare proportions (such as structured education) between groups. Data are means \pm SE unless stated otherwise.

\section{Results}

We studied 233 patients (Table 1): 126 males (54\%) and $107 \mathrm{fe}-$ males (46\%). Mean age was $44.2 \pm 1.0$ years and mean duration of diabetes was $22.4 \pm 1.1$ years; $105(45 \%)$ had previously attended structured education. All patients were using a basalbolus regime, with 212 patients (91\%) using analogue basal insulin and 223 (96\%) using analogue insulin for mealtime bolus.

Patients bringing a record book were older on average than patients either using a glucometer alone or neither a record book nor a glucometer (Table 1). There was no difference in the gender distribution between these groups and there was no effect of gender on $\mathrm{HbA}_{1 \mathrm{c}}$ (Table 1). Mean $\mathrm{HbA}_{1 \mathrm{c}}$ (Figure 1) did not differ between patients who brought a record book $(63 \pm 2 \mathrm{mmol} / \mathrm{mol}[7.9 \pm$ $0.2 \%]$ ) and patients who brought a glucometer $(63 \pm 2 \mathrm{mmol} / \mathrm{mol}$ $[7.9 \pm 0.2 \%]$ ); however, mean $\mathrm{HbA}_{1 \mathrm{c}}$ was significantly higher in the group with neither $(77 \pm 2 \mathrm{mmol} / \mathrm{mol}[9.2 \pm 0.2 \%] ; p<0.001$ vs. patients with either a record book or glucometer).

Patients who had or had not attended structured education had similar mean age $(45.0 \pm 1.3$ vs. $43.6 \pm 1.4$ years; $p=0.45)$ and mean $\mathrm{HbA}_{1 \mathrm{c}}(66 \pm 1 \mathrm{mmol} / \mathrm{mol}[8.2 \pm 0.1 \%]$ vs. $69 \pm 2$ $\mathrm{mmol} / \mathrm{mol}[8.5 \pm 0.2 \%] ; \mathrm{p}=0.13)$. There was also no difference in the method of recording SMBG between those who had or had not attended structured education (Table 1). For the 105 patients with prior attendance at structured education, mean $\mathrm{HbA}_{1 \mathrm{c}}$ was similar for those with a record book $(62 \pm 2$ $\mathrm{mmol} / \mathrm{mol}[7.8 \pm 0.2 \%], \mathrm{n}=46$ ) compared with a glucometer (66
Figure 1. Mean age-adjusted $\mathrm{HbA}_{1 \mathrm{c}}$ according to the method of recording SMBG data brought to routine clinic review

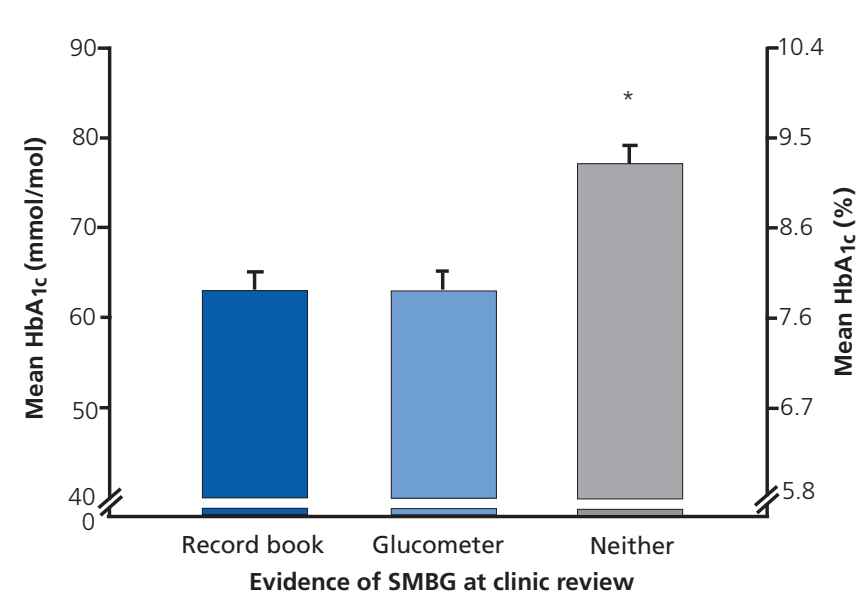

${ }^{*} p<0.001$ vs. patients with a record book or glucometer

SMBG: self-monitored blood glucose.

$\pm 2 \mathrm{mmol} / \mathrm{mol}[8.1 \pm 0.2 \%], \mathrm{n}=27)$. However, mean $\mathrm{HbA}_{1 \mathrm{c}}$ was significantly higher in the 32 patients with neither method of recording SMBG data $(73 \pm 2 \mathrm{mmol} / \mathrm{mol}[8.8 \pm 0.2 \%] ; p<0.03$ vs. record book or glucometer).

\section{Discussion}

These data indicate that evidence of the use of a record system, whether electronic or paper, brought to clinic is associated with significantly better control than not bringing either. Evidence of a written record of SMBG was not associated with better $\mathrm{HbA}_{1 \mathrm{c}}$ control compared with a glucometer alone.

SMBG includes an assessment of the glucose concentration (self-measurement) as well as the interpretation and response to the readings (self-regulation). It may be the case that transcribing the data is not necessary for the second process to occur. It has often been considered that the use of a logbook can help a patient to better understand the effect of food, exercise, sickness and medications on glucose levels. Furthermore, reflecting on the information with a logbook is expected to help explain any trends of dysglycaemia and allow planned responses. Since the 1990s, meters have had a built-in memory function and this may be facilitating review and reflection of data without the need for using a record book. ${ }^{9}$ Early trials testing the memory technology of glucometers found no superiority over the use of a written record. ${ }^{10,11}$ More recently, glucometers have gained the ability to record events such as carbohydrate intake and exercise, finessing the "virtual logbook" and potentially making written records obsolete.

SMBG is a fundamental component of structured education programmes for patients with type 1 diabetes. As part of the structured education course programme, a written record of patients' glucose control is brought to the sessions for discussion and analysis. Our data suggest that many patients are not con- 


\section{Key messages}

- Mean clinic $\mathrm{HbA}_{1 \mathrm{c}}$ did not differ between type 1 diabetes patients who used a book or glucometer to keep records of self-monitored glucose readings, but was higher in those who used neither

- Prior receipt of structured diabetes education did not predict use of a record book or glucometer in the clinic

- Self-reflection on glucose results is important for type 1 diabetes self-management, irrespective of the recording method used

tinuing the use of a written record after structured education. Surprisingly, we found no apparent added benefit to glycaemic control from using a capillary blood glucose monitoring diary in the group who had attended structured education. These data may help to advise and reassure those patients attending structured education that transcribing data is not essential to successful implementation of the philosophies of the course, but that the need to reflect on results remains significant.

Elderly patients were more likely to use a record book and to have lower $\mathrm{HbA}_{1 \mathrm{c}}$. It is known that SMBG is more likely to occur in the elderly. ${ }^{12}$ These behaviours may represent a 'survivor effect', as use of a written record may be a legacy of advice given during the advent of glucometer testing in the mid-1980s. Younger patients may be more comfortable with new technology, data handling and use of the meter.

It is important to recognise that the associations reported may have no causal basis. Patients without evidence of self-testing may have generally more detrimental self-management behaviour, such as sub-optimal concordance with pharmacological regimens. Patients with chronically poor control may become discouraged and stop testing (or recording), whereas patients who use a written record may be more motivated and concordant with general diabetes therapy. Only data presented at the clinic were considered and a patient may have used a record book but failed to bring it to the clinic appointment. Patients without a written record may have downloaded the data onto a home computer to facilitate evaluation of insulin therapy.

$\mathrm{HbA}_{1 \mathrm{c}}$ data are an accessible surrogate outcome for diabetes control, but we did not capture other aspects of diabetes care, such as hypoglycaemia frequency or quality of life/patient satisfaction. In particular, this study was not designed to assess the effect of frequency of testing or the quality of diabetes control as represented by home SMBG data. The effect of increasing frequency of testing has been described elsewhere.2,4 It remains to be seen whether the method of recording SMBG is associated with a 'proactive' or 'reactive' insulin strategy to hyperglycaemia. We do not know how often patients are testing, but the act of bringing the book to clinic perhaps is a marker of the degree of engagement and involvement in self-management.

Strengths of this study are its involvement of two sites in south London and its inclusion of an ethnically diverse population. They have similar access to and quality of healthcare. This study is timely as new-generation meters with trend pattern analyses are now coming on-stream, making future studies of this nature highly challenging. The results of this study suggest that use of such meters would not be associated with a worsening of control. It remains to be seen whether they can offer a further improvement in diabetes management.

Conflict of interest The authors declare no competing financial interests.

Funding No funding was received for this study.

\section{References}

1. National Institute for Clinical Excellence. Diagnosis and Management of Type 1 Diabetes in Children, Young People and Adults. Clinical Guideline 15. 2004.

2. Karter AJ, Ackerson LM, Darbinian JA, et al. Self-monitoring of blood glucose levels and glycemic control: the Northern California Kaiser Permanente Diabetes registry. Am J Med 2001;111:1-9. 1. National Institute for Clinical Excellence. Diagnosis and Management of Type 1 Diabetes in Children, Young People and Adults. Clinical Guideline 15. 2004.

2. Karter AJ, Ackerson LM, Darbinian JA, et al. Self-monitoring of blood glucose levels and glycemic control: the Northern California Kaiser Permanente Diabetes registry. Am J Med 2001;111:1-9

3. Simmons JH, Chen V, Miller KM, et al. Differences in the management of type 1 diabetes among adults under excellent control compared with those under poor control in the T1D Exchange Clinic Registry. Diabetes Care 2013:36:3573-7. http://dx.doi.org/10.2337/dc12-2643

4. Schutt $M$, Kern W, Krause $U$, et al. Is the frequency of self-monitoring of blood glucose related to long-term metabolic control? Multicenter analysis including 24,500 patients from 191 centers in Germany and Austria. Exp Clin Endocrinol Diabetes 2006;114:84-8. http://dx.doi.org/10.1055/s-2006-924152

5. Miller KM, Beck RW, Bergenstal RM, et al. Evidence of a strong association between frequency of self-monitoring of blood glucose and hemoglobin A1c levels in T1D Exchange Clinic Registry participants. Diabetes Care 2013;36:2009-14. http://dx.doi.org/10.2337/dc12-1770

6. Johansen MD, Gjerlov I, Christiansen JS, et al. Interindividual and intraindividual variations in postprandial glycemia peak time complicate precise recommendations for self-monitoring of glucose in persons with type 1 diabetes mellitus. J Diab Sci Technol 2012;6:356-61. http://dx.doi.org/10.1177/193229681200600221

7. Szypowska A, Ramotowska A, Dzygalo K, et al. Beneficial effect of realtime continuous glucose monitoring system on glycemic control in type 1 diabetic patients: systematic review and meta-analysis of randomized trials. Eur J Endocrinol 2012;166:567-74. http://dx.doi.org/10.1530/EJE-11-0642

8. Stevens JC. Applied Multivariate Statistics for the Social Sciences. Hillsdale, NJ: Lawrene Erlbaum; 1992.

9. Clarke SF, Foster JR A history of blood glucose meters and their role in self-monitoring of diabetes mellitus. Br J Biomed Sci 2012;69:83-93.

10. Laffel LM, Hsu WC, McGill JB, et al. Continued use of an integrated meter with electronic logbook maintains improvements in glycemic control beyond a randomized, controlled trial. Diabetes Technol Ther 2007;9 254-64. http://dx.doi.org/10.1089/dia.2006.0021

11. Strowig SM, Raskin P. Improved glycemic control in intensively treated type 1 diabetic patients using blood glucose meters with storage capability and computer-assisted analyses. Diabetes Care 1998;21:1694-8. http://dx.doi.org/10.2337/diacare.21.10.1694

12. Karter AJ, Ferrara A, Darbinian JA, et al. Self-monitoring of blood glucose: language and financial barriers in a managed care population with diabetes. Diabetes Care 2000;23:477-83. http://dx.doi.org/10.2337/diacare.23.4.477 